\title{
Learning PR. Methodological and legitimation-based learning in PR - A theoretical approach and empirical findings
}

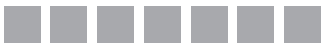 \\ Olaf Hoffjann \\ ostfalia UNIVERSITY OF APPLIEd SCIENCES, geRmany \\ Michael Lohse
}

OSTFALIA UNIVERSITY OF APPLIED SCIENCES, GERMANY

DOI: 10.19195/1899-5101.9.2(17).7

\begin{abstract}
PR increases the reflexivity of organizations, thereby providing a central opportunity for learning. While this consideration is implicitly contained in many definitions and theories relating to PR, organizational learning has until now remained a "hidden topic" in international PR research. This is all the more surprising when we consider that learning is relevant to PR on two counts at least: first, the aforementioned role of PR as a central learning opportunity within an organization. PR identifies stakeholder demands and develops strategies to help ensure the legitimacy of the organization. This will be referred to as legitimation-based learning. Second, PR learns with respect to its own methods and skills. This will be referred to as method-based learning.

This article will present a theoretical framework for legitimation-based and method-based learning. Then, the initial results of an online survey $(N=121)$ that examines selected issues relating to this approach will be presented.
\end{abstract}

KEYWORDS: organizational learning, reflexivity of organizations, public relations, online survey.

\section{CURRENT STATE OF RESEARCH}

\section{Definitions}

Broadly speaking, organizational learning can be defined as the reversal of tried and trusted structures (Baecker, 2003, p. 195). This broad understanding also takes account of incremental, almost imperceptible learning, where, from an evolutionary theory perspective, any variations are established at a very slow rate and are often unplanned (Luhmann, 2000, pp. 355-356). This is linked with doubts as to the potential of planning and management. As plausible as this criticism may be, it would make just as little sense to do away with schools and universities as to 
abolish institutions of organizational learning within organizations. We therefore propose a narrower understanding of learning and, more specifically, organizational learning:

Organizational learning occurs when members of the organization act as learning agents for the organization by detecting and correcting errors in organizational theory-in-use, and embedding the result of their enquiry in private images and shared maps of organization. (Argyris \& Schön, 1978, p. 29; Senge, 1990)

With this in mind, in the following, organizational learning will be understood as a deliberately instigated process, in which organizations question and unlearn existing structures (e.g. knowledge, applicable routines and standards).

In the case of legitimation-based learning, the focus is on knowledge, skills and rules e.g. concerning changes to (critical) stakeholders. This corresponds largely with the issues management approach. In the case of method-based learning, the focus is on knowledge, skills and rules relating e.g. to (new) media or methods of monitoring and evaluation. Method-based learning is vital among other things because legitimation-based learning depends to a great degree upon it. Therefore, learning PR must be understood as a relevant part of organizational learning, which takes internal as well as external learning resources and processes into account.

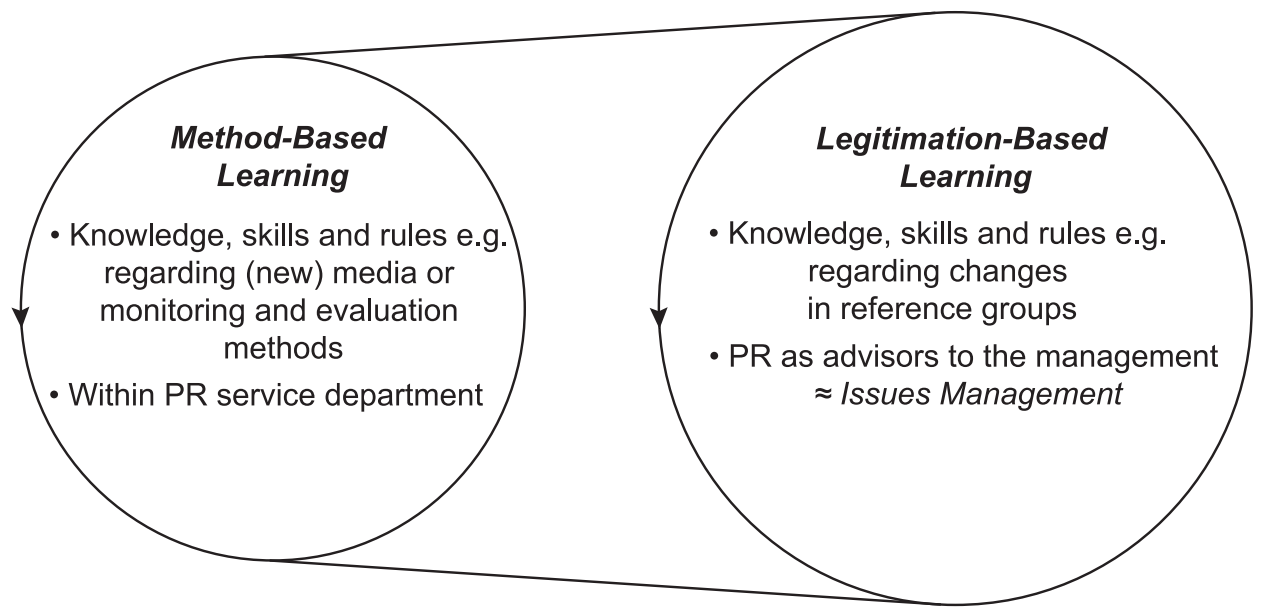

Figure 1. Method-based and legitimation-based learning

Source: authors.

\section{Learning and PR}

$\mathrm{PR}$ is one of the central learning opportunities within organizations. In PR research, this role is highlighted by the use of terms like "early warning system" or 
"reflexive capacity" (Jarren \& Röttger, 2009). As different as these terms are, what they have in common is that they attribute to PR the role:

[...] based on systematic environmental observations, (of feeding) information from the organization's surroundings relevant to legitimation and organization into the organization system reproduction. ${ }^{1}$ (Jarren \& Röttger, 2009, p. 44)

This relevance as an organizational opportunity for learning is also reflected in leading definitions of PR and approaches to the subject; by way of example, we refer here to Long and Hazleton's definition of PR:

PR is a communication function of management through which organizations adapt to, alter or maintain their environment for the purpose of achieving organizational goals. $(1987$, p. 6)

While learning implicitly plays a role in many definitions and theories of PR, it has barely been explored in international PR research thus far. In the following, the implicit and explicit role of the issue of learning will be explained in the discourse concerning legitimation-based and method-based learning.

\section{Legitimation-based learning}

In legitimation-based learning, learning considerations play a role in the research on PR beyond the basic theoretical considerations referred to above in two approaches in particular: in issues management and in the discourse on the influence of PR within organizations.

The concept of issues management focuses on the:

[...] management of organization and community resources to advance organizational and community interests and rights by striking a mutual balance with stakeholders and stakeseekers. (Heath \& Palenchar, 2009, p. 15)

The goal, among other things, is to identify potential issues as early as possible, thereby contributing to the societal acceptance and legitimacy of an organization. While the concept of issues management was developed almost 40 years ago, empirical research to date is still in short supply (Ingenhoff \& Röttger, 2013, p. 474). The proximity between the concept of issues management and organizational learning processes is underscored not least by the fact that links were made at an early stage between Weick's $(1979,2001)$ "process of organizing", (one of the leading approaches in organizational learning), and the concept of issues management (e.g. Dutton \& Duncan, 1987).

1 All translations from German are made by the authors. 


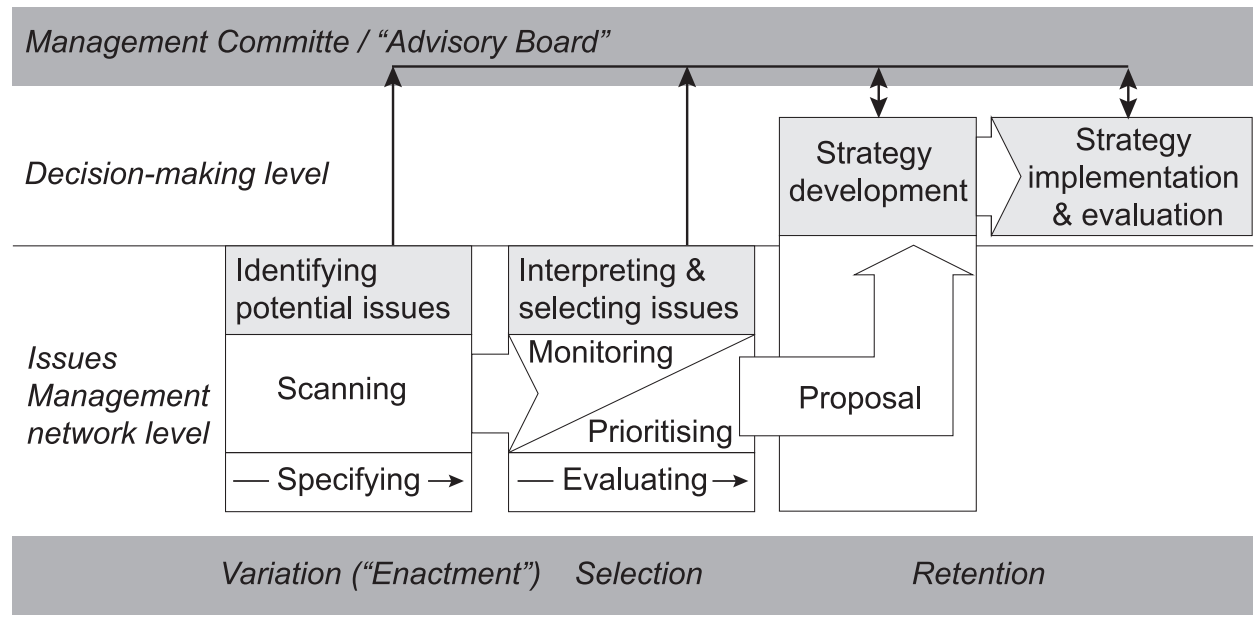

Figure 2. Issues management process following Weick

Source: Ingenhoff (2004, p. 110).

During the retention phase, the issues management approach also deals with the question of how issues considered important and strategies developed are taken into account by the management of the organization. Ultimately, this question relates to the status and influence of PR within an organization. Without this influence, $\mathrm{PR}$ is unable to exercise its role as a learning opportunity. Often, this is linked with the demand that PR ought to be afforded the role of a management function. Grunig et al. (2002, p. 159), concluded that excellent PR is encouraged where PR is a member of the dominant coalition within an organization. However, recent studies lead to the conclusion that the influence and status of PR is not as extensive as PR officers assumed (Zerfaß et al., 2014, p. 72). According to this understanding, variation cannot only be understood as environmental monitoring but also as a conscious learning process that includes e.g. the use of external consultants as well as participatory processes with stakeholders.

\section{Method-based learning}

In contrast to this, method-based learning has been largely ignored in PR-research. The way in which, for instance, PR develops with respect to new methodologies (e.g. communication controlling) and media (e.g. Social Media), has hitherto been examined in qualitative terms at best.

In their study, Hoffjann \& Röttger (2009) examined knowledge management of PR agencies in Germany. It became clear that activities to generate knowledge without specific queries were by and large limited to the personal knowledge and dedication of employees. Learning what has previously been learnt, to attain faster and more effective learning, is just as rare as reflexive learning, where organizations 
develop strategies that show first and foremost what needs to be learnt, and what the focus of that learning ought to be. On the whole, conditional programming dominates: events such as acquisition enquiries trigger routine processes (e.g. selecting the project team). Learning at the individual's initiative in the absence of acquisition enquiries or customer requests is seen rarely, if ever.

This result is even more sobering when compared with other types of organization (Hoffjann \& Gusko, 2013). Pursuant to this, learning processes and structures within agencies are more pronounced than those in non-profit organizations and companies.

Table 1. Learning in various types of organization

\begin{tabular}{|l|l|l|l|}
\cline { 2 - 4 } \multicolumn{1}{c|}{} & \multicolumn{1}{c|}{ Design } & \multicolumn{1}{c|}{ Selection } & \multicolumn{1}{c|}{ Retention } \\
\hline All & $\begin{array}{l}\text { Exchange between PR } \\
\text { employees }\end{array}$ & More informal proceedings & Server solutions \\
\hline Companies & $\begin{array}{l}\text { Intensive monitoring } \\
\text { Input from new employees } \\
\text { Professional networks }\end{array}$ & $\begin{array}{l}\text { Discussions and decision-making } \\
\text { processes with a long-term view } \\
\text { Influenced in part by hierarchical } \\
\text { structures }\end{array}$ & $\begin{array}{l}\text { Rules on } \\
\text { documentation } \\
\text { Internal talks and } \\
\text { training events }\end{array}$ \\
\hline Regular meetings & $\begin{array}{l}\text { Unsystematic } \\
\text { Focus on traditional mass } \\
\text { media }\end{array}$ & $\begin{array}{l}\text { Long-term decision-making } \\
\text { processes for relevant subjects } \\
\text { (sometimes with external advice) }\end{array}$ & $\begin{array}{l}\text { Presentations } \\
\text { subjects } \\
\text { Influenced in part by hierarchical } \\
\text { structures }\end{array}$ \\
\hline
\end{tabular}

Source: Hoffjann \& Gusko (2013).

The outline of the current state of research shows that there is a considerable degree of deviation between legitimation-based and method-based learning, both in practice and in the research. Across large parts of PR practice, method-based learning is barely evident in any differentiated form and, thus far, has been subject to scarcely any research. In contrast, legitimation-based learning can be found in a considerably more developed form, in particular in larger organizations, and has been researched far more intensively. In concrete terms, this means that the following considerations for method-based learning can be understood as a kind of prototype for the development of a concept, while for legitimation-based learning, they can be used to identify gaps in the research.

\section{ORGANIZATIONAL THEORY FRAMEWORK AND RESEARCH OUESTIONS}

The functional and interpretative paradigms provide the theoretical framework. The systems theoretical perspective, in the form proposed by Luhmann (1996), is taken as the functional approach. A central assumption of systems theory is that social systems need to reduce complexity in order to establish social order. In organiza- 
tions, the structures that have been developed to this end are largely redundant, and are used to process similar problems according to the same rules and routines in each case. This is one of the key advantages of organizations, and enables them to resolve complex tasks. The disadvantage can be seen in bureaucratic organizations: they no longer question their routines; they stagnate and as a result are increasingly unable to respond to new developments. According to a systems theory perspective, this results in the need for complexity to be increased again, in order e.g. to be able to reveal "blind spots" and monitor as-yet unfamiliar developments. With reference to system theory, the theory framework can immediately be connected to the main works of organizational theory like Senge's (1990) "The Fifth Discipline."

We hope to be able to answer the question as to how PR deals with this additional complexity using the process of organizing according to Weick $(1979,2001)$, which is an interpretative approach. With his process of organizing, Weick demonstrated how ambiguity is reduced within organizations by means of recurrent sense-making processes.

Both theoretical perspectives highlight the contrast between organizing and learning:

Organizing and learning are essentially antithetical processes [...]. To learn is to disorganize and increase variety. To organize is to forget and to reduce variety. (Weick \& Westley, 1996, p. 440)

This approach between variety and obsolescence leads to three differences to be tackled; our three research questions are derived from these:

Table 2. Conflicts between variety and obsolescence and the resulting questions

\begin{tabular}{|c|c|c|c|}
\hline & Variety & Redundancy & Research questions \\
\hline $\begin{array}{l}\text { Organizational } \\
\text { Learning }\end{array}$ & $\begin{array}{l}\text { Oxymoron: } \\
\text { Learning creates } \\
\text { variety... }\end{array}$ & $\begin{array}{l}\text {... Organizing means } \\
\text { reducing variety (Weick } \\
\text { \& Westley, 1996, p. 440). }\end{array}$ & $\begin{array}{l}\text { How is complexity } \\
\text { increased and subsequently } \\
\text { reduced in formalized } \\
\text { learning processes? }\end{array}$ \\
\hline $\begin{array}{l}\text { Opportunities and } \\
\text { risks of learning } \\
\text { and learning } \\
\text { structures }\end{array}$ & $\begin{array}{l}\text { Learning entails } \\
\text { opportunities } \\
\text { and risks... }\end{array}$ & $\begin{array}{l}\text {... Not learning entails } \\
\text { opportunities and risks } \\
\text { (Kühl, 2000). }\end{array}$ & $\begin{array}{l}\text { How do formalized learning } \\
\text { processes deal with the } \\
\text { differences between } \\
\text { tradition and innovation? }\end{array}$ \\
\hline $\begin{array}{l}\text { Reflection in } \\
\text { formalized } \\
\text { learning processes }\end{array}$ & $\begin{array}{l}\text { Even proven } \\
\text { learning } \\
\text { strategies should } \\
\text { be reviewed } \\
\text { (Baecker, 2003). }\end{array}$ & $\begin{array}{l}\text { A specific learning } \\
\text { strategy can be precisely } \\
\text { what accounts for an } \\
\text { organization's success. In } \\
\text { some areas, organiza- } \\
\text { tional learning is less } \\
\text { important (e.g. municipal } \\
\text { offices). }\end{array}$ & $\begin{array}{l}\text { How are learning and } \\
\text { formalized learning } \\
\text { processes reflected? }\end{array}$ \\
\hline
\end{tabular}

Source: authors. 
In organization theory terms, legitimation-based and method-based learning can be conceived as follows: method-based learning refers almost exclusively to the PR itself: from identification, to interpretation, through to selection, all phases take place within PR. By contrast, in legitimation-based learning, in the case of farreaching issues, $\mathrm{PR}$ can only make recommendations to the management, while other departments of the organization are involved in the identification and interpretation. Here, PR takes on more the role of a moderator.

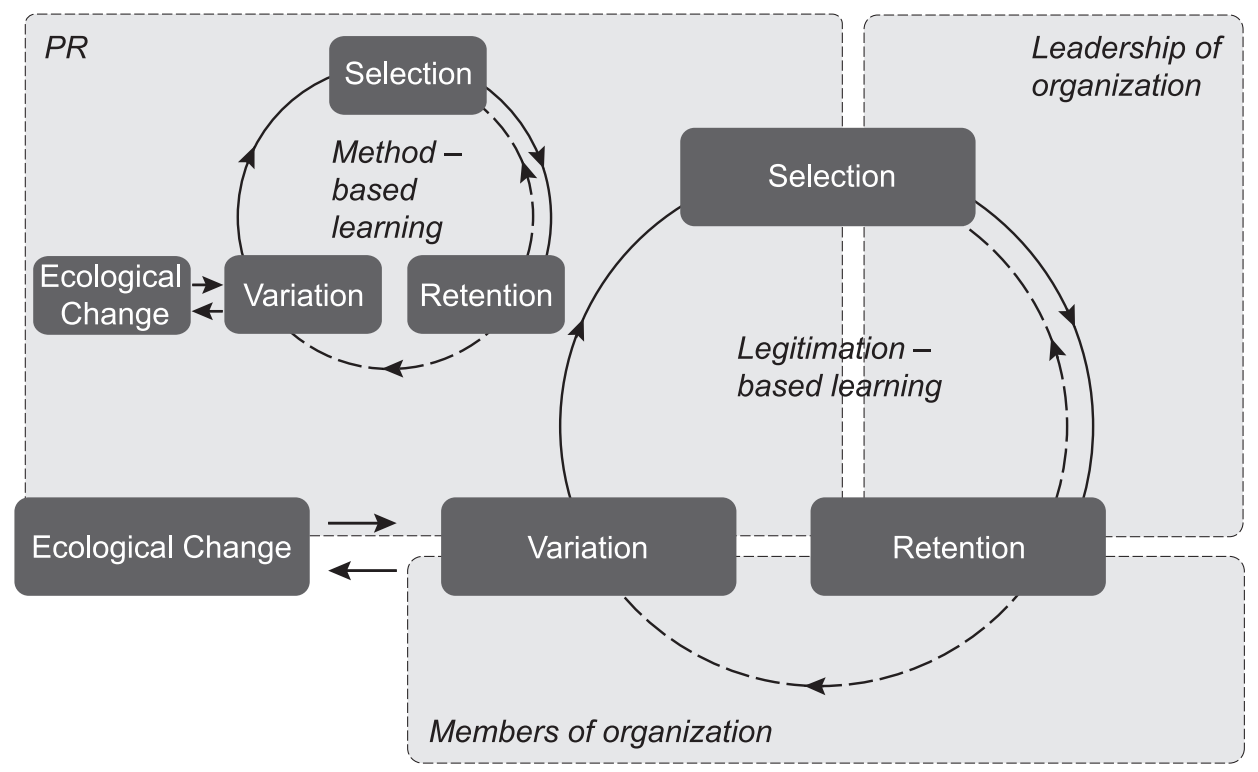

Figure 3. Method-based and legitimation-based learning within PR

Source: authors, expanding on Weick (1979).

\section{How is complexity increased in formalized learning processes?}

The aim of the process of organizing is to specifically create variations and opportunities for interpretation. Organizations need to be garrulous, clumsy, superstitious, hypocritical and monstrous (Weick, 1979; Luhmann, 2000).

It is to this end that there are formalized learning structures such as issues management, innovation management, executive meetings, consumer associations, ombudsmen, etc. This specifically increases complexity and reflexivity. All of these formalized learning structures are as a rule extremely resource-intensive, and, thus, expensive. Along with the third question, we will discuss below how an appropriate level of learning structures can be found.

However, the success of all of these formalized learning structures is greatly dependent on a culture of learning and innovation, which in the literature on issues management in particular is examined in terms of participative culture. Formalized 
learning structures can be seen as an indicator of a culture of willingness to learn. After all, formalized learning structures, like a customer panel or company suggestion box, can be successful only if there is a pronounced learning culture. If learning is a process of strengthening variations (Baecker, 2003, p. 182), then it needs a culture in which the communication of those observed variations is not penalized.

The relevance of the organizational culture becomes clear in the context of legitimation-based learning. Thus far, this has been touched on briefly at best within issues management research (e.g. Ingenhoff, 2004). In addition to a participative culture, issues of error and innovation culture must also be examined here, since these influence the extent to which an organization is ready, in terms of its mentality, for change.

\section{How do formalized learning processes deal with the differences between tradition and innovation?}

In the literature, learning and change are often inflated and glorified, leaving the potential risks of decisions relegated to the background (e.g. Senge 1990). Sometimes, however, change appears to take place for change's sake: new company management that issues an external consultancy job or installs in-house risk management systems will tend to follow these recommendations simply in order to legitimize its investment decisions. In short: there can be various reasons why the consequences of a learning decision are viewed from one perspective only. In these instances, only the "for" or only the "against" are discussed.

There are various strategic solutions to this problem. Balance can be ensured, for instance, if executive bodies include representatives of both sides of an argument. Where this is not the case, attempts should at least be made in internal discussions to actively identify the potential risks and disadvantages of a decision. Another approach could be not to award bonuses for change. This can help to go some way towards preventing problems such as in-house advisors initiating changes solely in order to obtain such rewards.

Ultimately, the (un)willingness to learn within an organization must be seen in a competitive context. If an organization always succumbs to stakeholder demands, this may jeopardize its long-term existence - but in the short term, it may also threaten that of competitors. Thus, organizations observe the extent to which their competitors are willing to learn and will adjust accordingly.

Consequently, the question of whether learning or not learning is the more appropriate decision can in some instances only be evaluated ex post. However, it makes sense to rationally explain the advantages and disadvantages, opportunities and risks from all perspectives in order, for example, to avoid subconscious adaptation.

Beyond this irreconcilable contradiction, organizational learning is nevertheless worthwhile if it is understood as a myth of rationality. Kühl refers to this as the "rainmaker effect" (Kühl, 2000, pp. 163-164) beyond the intended effects, the guid- 
ing principle of organized learning encourages the ability to test something within the relatively conservative setting of an organization.

\section{How do organizations reflect upon learning and formalized learning processes?}

At the latest since the studies by Bateson (1972) and Argyris \& Schön (1978), we have known that learning occurs on various levels. Even if there have been other staged concepts recently developed (Kirsch, 1992; Pawlowsky, 1995; Probst \& Büchel, 1994; Senge, 1990), they largely correspond with each other (Blank, 2004). Each higher level is able to see the blind spots of the lower levels: "Single-loop learning" can be used to investigate whether the planned objectives - e.g. the profitability of a project - have been attained. "Double-loop learning", meanwhile, can be used to question the objectives and investigate any unintended side-effects. In the context of legitimation-based learning, this includes for example the question of which problems short-term profitability considerations could trigger in the medium-term (Argyris \& Schön, 1978). On the third level, organizations learn to learn - Bateson referred to this as Deutero-learning (Bateson, 1972, pp. 159-176). Here, organizations reflect upon whether they learned correctly in the past - and whether they ought, perhaps, to change anything in future. In the course of legitimation-based learning one could ask, for instance, whether conclusions were in fact drawn from undesirable developments in the past.

However, these levels do not sufficiently deal with the issue of what are appropriate levels of learning resources and willingness to learn. The competitive perspective in particular is at best taken into account implicitly in this context. In order to find an appropriate measure, therefore, a fourth level should be added, which will be referred to as contextual learning: how do I learn in comparison (a) to the competition and (b) to organizations in other markets? The PR department of a chemicals company, for example, could on the one hand observe the learning efforts of its direct competitors and, on the other hand, the learning of other companies producing industrial goods, which are not direct competitors, but nevertheless display several similarities. This would allow it to learn from the learning of others, but above all would enable it to establish whether it learns too much or not enough. While this observation of competitors initially costs resources, it can result in resources being "cut" in future if it transpires that the organization invests significantly more resources in institutional reflexivity than others, without experiencing commensurate success. Or, alternatively, competitive opportunities could be increased if an organization establishes that it is not investing enough in learning and is at a competitive disadvantage as a result. Here, at the latest, the competitive nature of learning becomes clear.

Issues management research has examined the third level at most (Ingenhoff, 2004). This gap is all the more striking given that issues of legitimation ought always to be seen from a competitive perspective. 


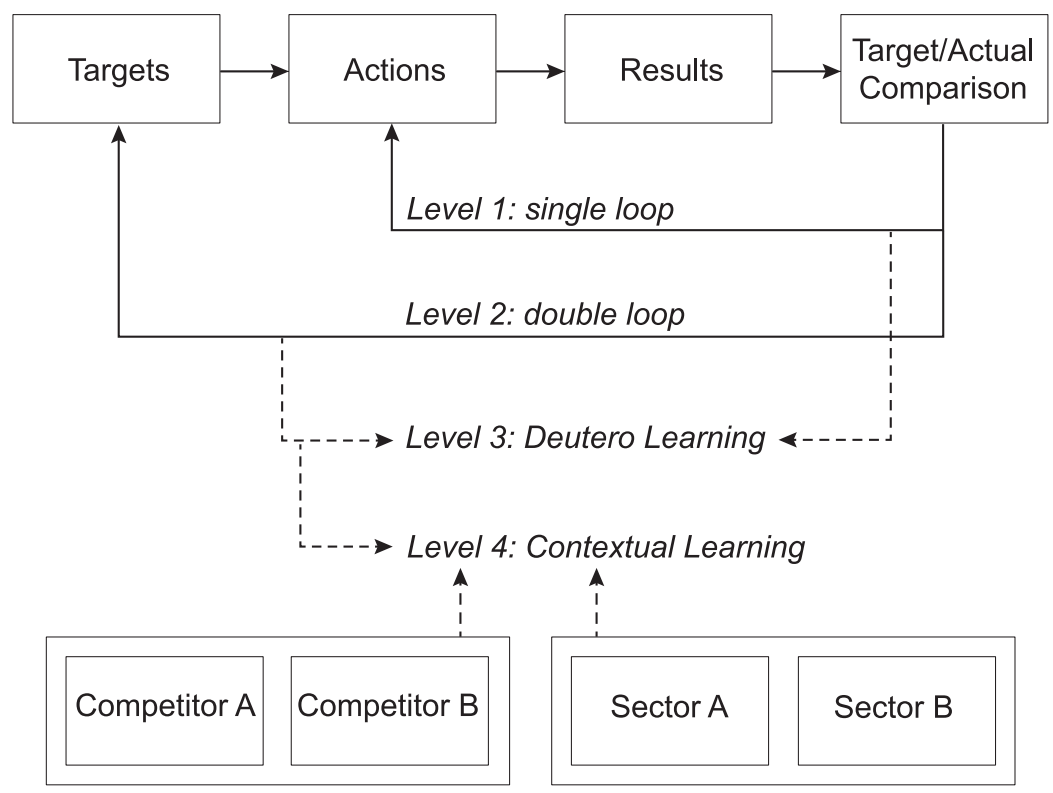

Figure 4. Levels of learning

Source: authors, expanding on Argyris \& Schön (1978).

\section{METHODOLOGY}

Within the framework of a more comprehensive project concerning the potential of participative corporate structures, we conducted our survey between April 2014 and March 2015 in a total of three waves among 1,473 individuals responsible for PR and marketing, as well as managers from small and medium-sized enterprises (which influence the field of investigation considerably) in the German food industry, as well as major corporations. Within this framework, it was also possible to investigate individual aspects of the aforementioned research questions. The results outlined in the following are based on a research section answered by 121 individuals responsible for PR and management and focuses on the main issues of corporate culture, participation of stakeholders, as well as the processes of reflection and acceptance of the company among its stakeholders.

\section{RESULTS}

The data provides insights into the formalized learning structures and processes, the (learning) culture of the surveyed companies and the links between these. The focus was on formalized learning processes, providing a first building block to help answer the research question. Specifically, this provided answers to the following selected issues: 
- What are the links between the learning structures within an organization and its (learning) culture?

- Which role does the learning context in which an organization is situated play in relation to the learning structures and processes?

Initially, the formalized learning structures and processes are examined, then the (learning) culture and finally the learning context that distinguish the surveyed company. Within the chapter, both descriptive results and correlations are explored. ${ }^{2}$

\section{Formalized learning structures and processes}

One of the central issues for learning in organizations is the question of how complexity can be increased. One of the key answers for learning with respect to PR is relatively obvious: by means of lively exchange with the stakeholders. The frequency of such an exchange is an indicator of the intensity of the learning processes. In the study, we asked about forms and frequency of correspondence between the company and the stakeholders. A distinction was drawn between PR-measures according to the fields of information, dialog and participation - inspired by Arnstein's "eight rungs on the ladder of citizen participation" (Arnstein, 1969, p. 217): mere contact, e.g. in the form of the provision of information to a stakeholder, is not sufficient to bring about PR learning. Instead, higher levels of participation need to be achieved to bring about exchange and, thus, learning. When it comes to learning activities, involvement is most stimulating and dialog least stimulating.

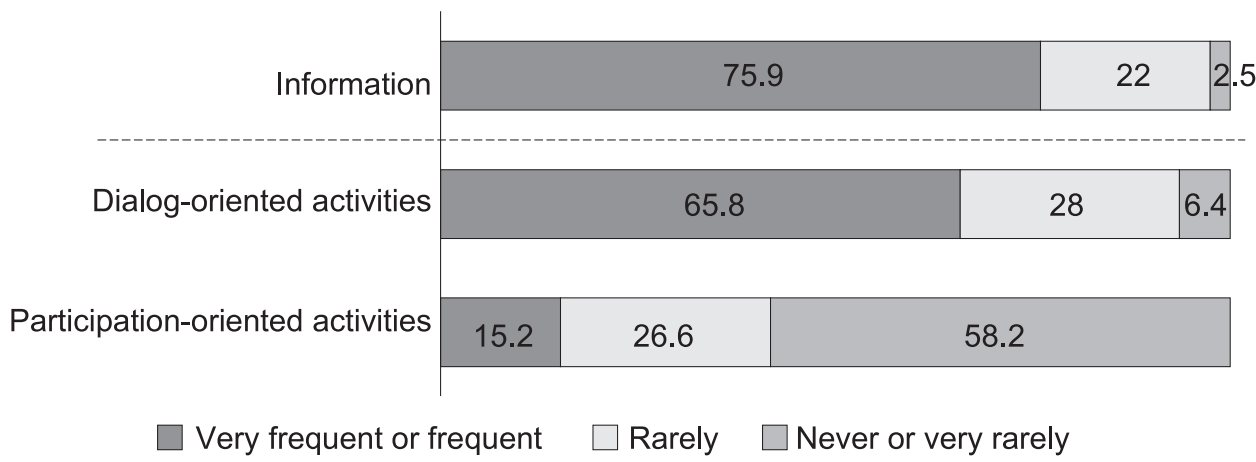

Figure 5. Frequency of PR-activities in the companies surveyed: "How often do you offer the following PR-activity?" Average value for all selected stakeholders; $N=79$ (in percent)

Source: authors.

2 The central relevant criterion here is the strength of the correlations between the examined variables. These would have to be moderate at least. The ranking correlation coefficient KenndallTau-b was calculated in order to evaluate the hypotheses. The advantages of this are that it is more resilient to deviations and small $\mathrm{n}$-figures. 
$75.9 \%$ of the companies surveyed inform their stakeholders (very) frequently. Dialog-oriented activities are provided (very) frequently by $65.8 \%$ of companies. Only $15.2 \%$, however, offer participation-oriented activities; $58.2 \%$ have these very seldom or indeed never. In addition, the survey contained questions relating to the intentional design of organizational learning and knowledge management: $46.2 \%$ of companies agree fully or more or less that this is a deliberate process; $31.3 \%$ rather not or not at all. Thus, more than half of the companies surveyed tackle organizational learning and knowledge management without any form of concept.

A second key factor that needs to be taken into account with regard to learning structures is the process of reflection. Continuous comparisons of target and actual and the actions and targets of the organization are at the core of organizational learning. Here, we asked how work, current conditions, corporate structures or other processes are reflected upon within the company. A distinction was drawn between continuity of processes of reflection and the issue of whether these processes of reflection involve external resources, such as consultants, customers or local residents. This is relevant because it helps to identify "blind spots" in self-perception and boosts the diversity of learning input during the process of reflection.

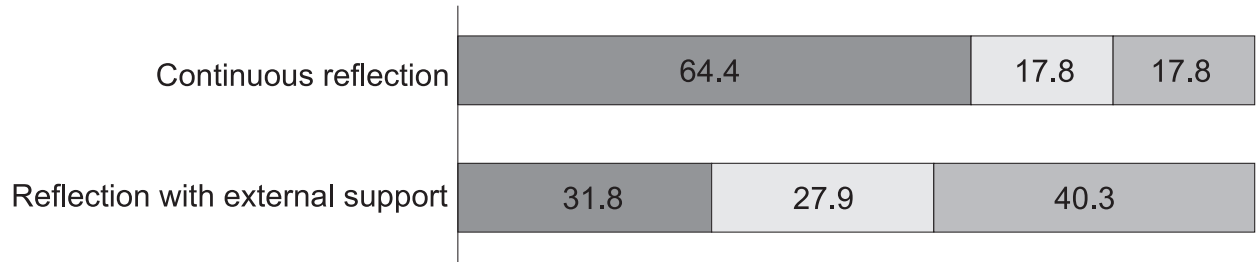

Agree or rather agree $\square$ Neither agree nor disagree $\square$ Don't agree or rather don't agree

Figure 6. Processes of reflection in the companies surveyed: "How do you reflect upon your work, the current situation, corporate structures and processes?" $N=152-154$ (in percent)

Source: authors.

A total of $64.4 \%$ of respondents continually reflect upon work, conditions, corporate structures and processes. Only $17.8 \%$ do not. A further $31.8 \%$ of the companies furthermore often involve external resources in the process of reflection, whereby $40.3 \%$ do not really do this, or do not do this at all. Thus, it is clear that almost two-thirds use a continuous process of reflection as the foundation for a learning process within the company. However, it is also clear that only around a third of companies regularly involve external input, thereby increasing the diversity of the learning processes and tackling "blind spots."

The third key factor for the design of learning activities and processes is the context in which PR-learning takes place. We therefore asked how important corporate legitimation is as a rule and to what degree this is currently at risk. The outcome was ambivalent: the companies surveyed consider their current acceptance within society for the most part to be (very) high. Thus, the companies appear 
to be subject to rather limited pressure to learn. The figure of $76 \%$ of companies furthermore acknowledged that the relevance of acceptance of the company for its commercial success is high or very high. This provides a good basis for PR learning in the surveyed companies.

A significant link can be seen between the relevance of acceptance of the company to commercial success and the learning processes: the more relevant legitimation is for the (commercial) success of a company, the more likely that work, conditions, corporate structures and processes will be reflected upon a) continuously and b) with the involvement of external parties. Here we see a moderate rank correlation between the relevance of acceptance to commercial success and a) the continuousness of reflective activities, as well as b) the involvement of external resources. $^{3}$

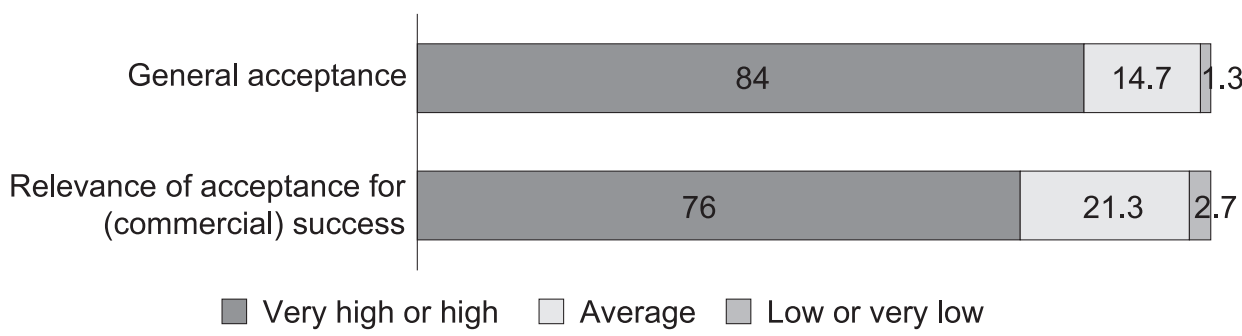

Figure 7. Evaluation of acceptance of companies surveyed: "How would you estimate the general acceptance of your company?" and "How important do you consider the acceptance of the company to be with respect to (commercial) success?" $N=75$ (in percent)

Source: authors.

\section{Learning culture}

Organizational learning means the creation and reduction of variation (Weick \& Westley, 1996, p. 440), opportunities and risks (Kühl, 2000) as well as the revision of proven learning strategies (Baecker, 2003). These links between organization and learning provide a rough indication of the core cultural dimensions: the culture of the organization must permit variation. To this end, it needs broad room for maneuver for the employees involved in organizational learning and must be able to compensate for uncertainties and risks. A decisive management can seize opportunities. Too many hierarchical levels can complicate organizational learning, e.g. through longer decision-making processes. A good relationship of trust between staff and their superiors, in turn, appears to be of key importance for the employee's scope to take decisions and deal with uncertainty. Willingness to change, as part

3 a.) Continuity reflexion; $=0.404 ; \mathrm{p}=0.000$; b.) Inclusion of external resources in the process of reflection; $=0.423 ; \mathrm{p}=0.000$. 
of the corporate philosophy, is at least a formal indication of the existence of a learning culture in the company. ${ }^{4}$

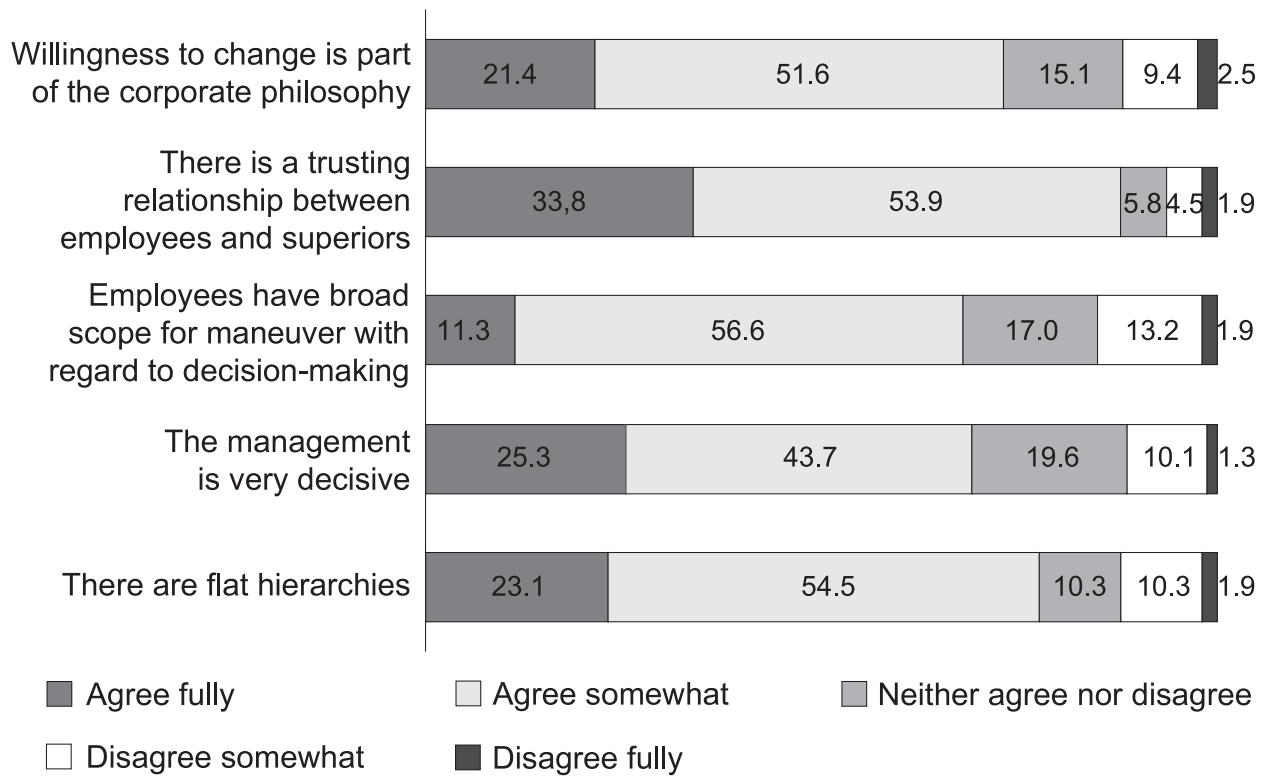

Figure 8. Cultural dimensions of companies surveyed: "How would you describe the culture and structure in your company?" $N=156-159$ (in percent)

Source: authors.

Table 3. Correlation values between the "conscious design of organizational learning and knowledge management" and the various cultural dimensions; ${ }^{\star *}$ significant correlation

\begin{tabular}{|l|c|c|c|}
\hline \multirow{2}{*}{$\begin{array}{l}\text { How would you describe the culture or structure in } \\
\text { your company? }\end{array}$} & \multicolumn{3}{|c|}{$\begin{array}{c}\text { Organizational learning and knowledge } \\
\text { management are intentionally structured. }\end{array}$} \\
\cline { 2 - 4 } & Kendall-Tau-b & $\mathrm{p}$ (2-sided) & $\mathrm{n}$ \\
\hline There are flat hierarchies. & .185 & .006 & 158 \\
\hline Management is very decisive. & $.327^{* *}$ & .000 & 158 \\
\hline $\begin{array}{l}\text { Employees have broad scope for maneuver as } \\
\text { regards decision-making. }\end{array}$ & $.433^{* *}$ & .000 & 159 \\
\hline $\begin{array}{l}\text { The employees and their superiors have a trusting } \\
\text { relationship. }\end{array}$ & $.494^{* *}$ & .000 & 154 \\
\hline $\begin{array}{l}\text { Willingness to change is part of the corporate } \\
\text { philosophy. }\end{array}$ & $.428^{* *}$ & .000 & 159 \\
\hline
\end{tabular}

Source: authors.

4 This list of cultural dimensions does not claim to be exhaustive, but is well-founded on both theory and our own advisory practice. 
Overall, the approval ratings for the cultural dimensions are high across the board. Based on this, the link between the cultural dimensions and the formalized learning structures and processes, as well as with the learning context, need to be examined. Basically, it can be assumed that: a) the flatter the hierarchies b) the more decisive the management, $c$ ) the greater the employees' autonomy d) the more developed the trust between employees and their superiors and e) the more willingness to change is part of the corporate philosophy, the more pronounced is the conscious design of organizational learning and knowledge management.

The examination of the correlation values shows with respect to the design of formalized learning structures that the link with the cultural dimensions needs to be viewed in a differentiated manner. There is a moderate correlation between the conscious design of organizational learning and knowledge management and almost all cultural dimensions. Only the issue of a) how flat the hierarchies are does not play a role.

\section{LEARNING TYPOLOGY OF ORGANIZATION}

The links described in the preceding parts provide the foundations upon which a learning typology of organizations can be developed, intended to help us to understand, relatively simply, whether an organization is more a fully developed learning type or whether it is, for instance, a "closed shop" with no interest whatsoever in PR learning. When developing the ideal types, we followed the ideal type

Table 4. Developing ideal types of learner: overview of relevant dimensions, including form (++ = most pronounced form, -- =least pronounced form)

\begin{tabular}{|c|c|c|c|c|c|c|c|c|c|}
\hline & 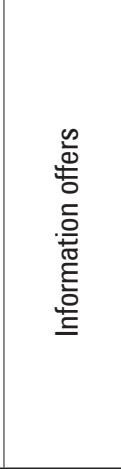 & 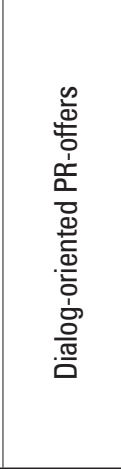 & 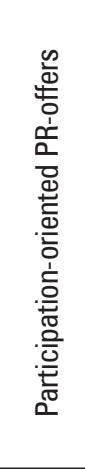 & 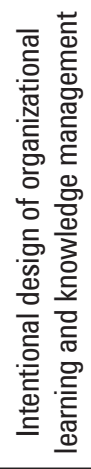 & 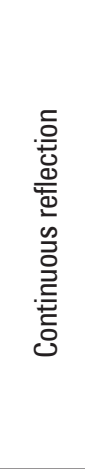 & 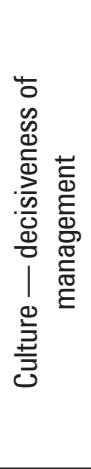 & 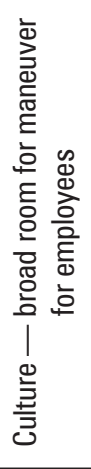 & 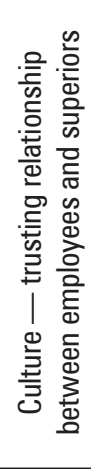 & 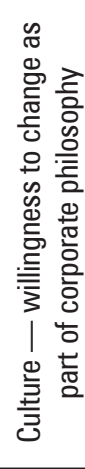 \\
\hline Learner & $\begin{array}{c}--/- \\
10 /+/++\end{array}$ & $\begin{array}{c}--/- \\
10 /+/++\end{array}$ & $+/++$ & $+/++$ & $+/++$ & $+/++$ & $+/++$ & $+/++$ & $+/++$ \\
\hline $\begin{array}{l}\text { Façade } \\
\text { type }\end{array}$ & $\begin{array}{c}--/- \\
/ 0 /+/++\end{array}$ & $++/+/ o$ & - & $+/ 0$ & o/-/-- & $--/-$ & $--/-$ & $--/-$ & $--/-$ \\
\hline $\begin{array}{l}\text { Anti- } \\
\text { learner }\end{array}$ & $\begin{array}{c}--/- \\
/ 0 /+/++\end{array}$ & -- & -- & $-/--$ & -- & $--/-$ & $--/-$ & $--/-$ & $--/-$ \\
\hline
\end{tabular}

Source: authors. 
as defined by Max Weber: we do not want to replicate reality one-to-one, but instead to create the learning typology of the organization according to a number of outstanding typical characteristics. Details and special features are ignored in order to be better able to reach the item to be investigated (Weber, 1904, pp. 125-126).

For the learning typology we define the following possible types: the "learner", the "façade type", the "anti-learning type" and the "non-specific learning type". The following factors were key to our approach:

- How often are participation-oriented formalized learning activities carried out?

- How conscious is the design of organizational learning and knowledge management?

Only if an organization answers these questions as positively as possible does it come into consideration for the distinctive types of learners. Furthermore, the learning culture and continuity are additional factors that also need to be taken into account, and help to differentiate between the pronounced learner and the other types of learners.

The learner represents an organization that involves its stakeholders very frequently or frequently in participation-oriented learning activities; which intentionally designs learning and knowledge management; which continuously reflects upon work, conditions and processes within the organization and has a learning culture at the highest level. The façade type carries out dialog-oriented learning activities with its stakeholders seldom at most. Participation-oriented learning offers are never performed, organizational learning and knowledge management are, however, by all means designed deliberately - particularly with regard to visible activities. However, work, conditions and processes within the organization are reflected upon more as-and-when necessary, rather than continuously and a learning culture is (rather) not present. This describes a type of learner that, while it professes outwardly that it is willing to learn, this is not reflected internally. The anti-learning type differs from the façade type in that it does not perform any dialog-oriented formal learning activities, learning and knowledge management are (rather) not designed deliberately and work, conditions and processes of the organization are reflected upon only as and when necessary. The non-specific learning type encompasses all organizations that cannot be allocated to any of the other types of learners. Applied to the study data, this provides the following picture ${ }^{5}$ :

As was to be expected, the types of learners are represented in the study group to a limited extent only, since these are ideal types. Nevertheless, $18.9 \%$ can be characterized as the façade type. Thus, a good $30 \%$ of the companies examined display learning activities outwardly. The large proportion of non-specific learners

5 The learning types were calculated initially in the form of an additive index. When-if-conditions ensured that the cases in the value range of the pronounced learning types also fulfil the requirements. If this was not the case, they were re-categorized as non-specific learners. 


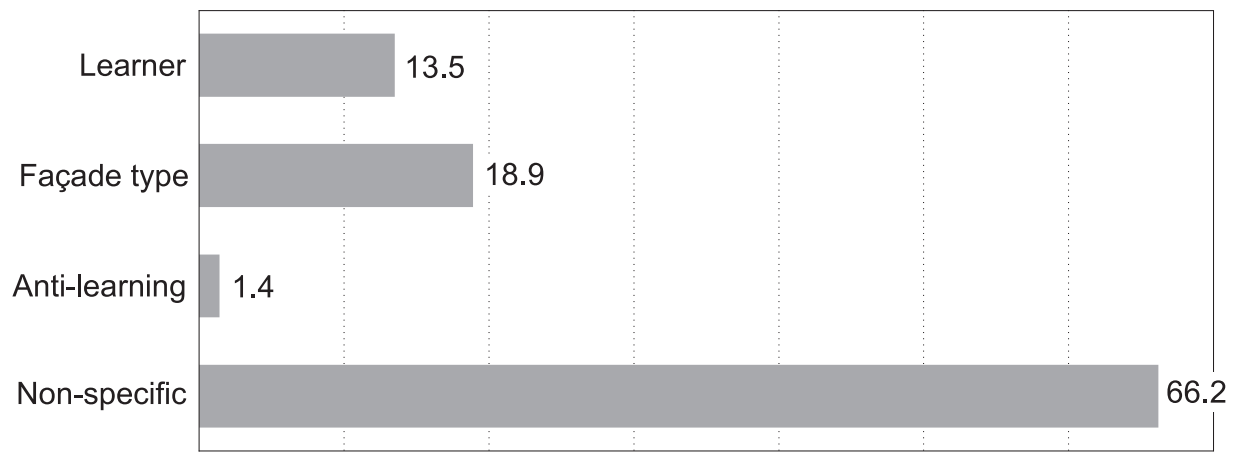

Figure 9. Frequency distribution of the various types of learner; $N=79$ (in percent)

Source: authors.

clearly shows that the companies surveyed differ greatly. The majority offers dialogoriented learning activities and consistently reflects upon work, conditions, corporate structures and processes. However, only around half of the companies design their organizational learning and knowledge management in a deliberate fashion. With regards also to the cultural factors - decisiveness of the management, broad scope for employees to take decisions and readiness to change as a part of the corporate philosophy - there are many companies in which these values are not positively established.

\section{CONCLUSIONS}

The empirical study showed that the companies surveyed generally have good (cultural) prerequisites for learning PR, but the learners, as an ideal type of learners, can, in practice, rarely be found. This is not surprising, because learning PR, as a part of the learning organization, is bound by many conditions that must be fulfilled (Senge, 1990). Three problem areas become apparent: First "learning PR" appears to be something for the elite of organizations, as the culture of the companies examined demonstrates. This suspicion is strengthened by the fact that decisionmaking freedom is one of the central factors for the intentional design of organizational learning and knowledge management. Second, there appears to be a particular hurdle between dialog-oriented and participation-oriented learning activities. This means that the learning activity of PR is confined to a low level. Third, while learning activities and processes are performed, external input is not involved, which constitutes a particular risk of "blind spots," thereby weakening learning activities considerably.

The learning context of an organization has clear links with its activities of reflection. This result is true both in terms of the consistency of reflection and the involvement of external sources. However, this is ambiguous: continuous reflection and the involvement of external resources can make us sensitive to the importance 
of acceptance for the success of the company. At the same time, the finding that the legitimacy of an organization is key to its success can also be viewed as the basis for the activities of learning PR. This is because it is only on account of this relevance that the necessary use of resources for learning activities is legitimized. After all, it was clearly apparent that the (learning) culture of an organization plays a significant role for the intentional design of organizational learning and knowledge management.

As regards the theoretical approach of "learning PR", these results as a whole mean that a more precise distinction needs to be drawn between those who learn in the organization and the means by which PR learns; weaknesses are revealed here that need to be examined in detail and adjusted accordingly in future research. Senge (1990) provides here approaches for a perspective that looks at the members of organizations. Nevertheless, the results can also be interpreted such that the differences between dialog-oriented and participation-oriented learning activities simply reflect the contradictions described in the theory between the increase in and reduction of complexity. The differences between intentionally designed organizational learning and knowledge management and learning activities could also reflect the conflict between tradition and innovation. In this context, deliberately designed learning activities can be conceived as risky innovations that are implemented cautiously. In contrast, dialog-oriented contacts with stakeholders are a traditional task of PR and constitute an integral part of safe exchange with the environment. These considerations would also need to be explored in more depth in future studies. The questions that could be examined include: why and in which form are learning decisions viewed only from a single perspective? Which solutions are found in practice and why? When can a decision in favor of or against learning be considered appropriate?

Yet more questions remain unanswered: a quantitative study could review the results found by Hoffjann \& Gusko (2013) on method-based PR learning and set these against a broad empirical basis. A qualitative research design could be used to examine the specific manifestations of reflection upon formalized learning processes. On what grounds is which learning level targeted? How are the organization's blind spots identified and, if applicable, avoided?

On the whole, these findings can provide new starting points for issue management research and the sociology of organizations, as well as expanding the general understanding of PR and helping to improve its image.

\section{REFERENCES}

Argyris, Ch., Schön, D.A. (1978). Organizational Learning: A Theory of Action Perspective. Massachusetts: Addison-Wesley Publishing Company.

Arnstein, S.R. (1969). A ladder of citizen participation. Journal of the American Planning Association, 35 (4), pp. 216-224.

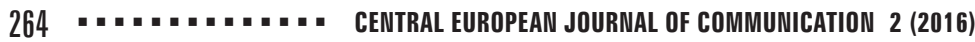

Central European Journal of Communication vol. 9, no 2 (17), Fall 2016

(C) for this edition by CNS 
Baecker, D. (2003). Organisation und Management. Frankfurt am Main: Suhrkamp.

Bateson, G. (1972). Steps to an Ecology of Mind: Collected Essays in Anthropology, Psychiatry, Evolution, and Epistemology. Chicago: University Of Chicago Press.

Blank, S. (2004). Evaluation im Kontext des organisationalen Lernens: der Beitrag reflexiver Bewertungsoperationen zur Entwicklung lernender Systeme. Tübingen: NN. Retrieved April 15, 2016 from http://nbn-resolving.de/urn:nbn:de:bsz:21-opus-21083.

Dutton, J.E., Duncon, R. (1987). The creation of momentum for change through the process of strategic issue diagnosis. Strategic Management Review, 8, pp. 279-295.

Grunig, L.A., Grunig, J.E., Dozier, D.M. (2002). Excellent Public Relations and Effective Organizations. A Study of Communication Management in Three Countries. Mahwah: Routledge.

Heath, R.L., Palenchar, M.J. (2009). Strategic Issues Management: Organizations and Public Policy Challenges. Thousand Oaks, CA: SAGE Publications.

Hoffjann, O., Gusko, J. (2013). Evolution der PR. Eine Studie zum Wandel der PR. Zeitschrift für Kommunikationsökologie und Medienethik, 13 (1), pp. 53-63.

Hoffjann, O., Röttger, U. (2009). Wissensmanagement in PR-Agenturen. In: U. Röttger, S. Zielmann (eds.). PR-Beratung. Theoretische Konzepte und empirische Befunde. Wiesbaden: Springer Fachmedien, pp. 125-147.

Ingenhoff, D. (2004). Corporate Issues Management in multinationalen Unternehmen. Wiesbaden: Springer-Verlag.

Ingenhoff, D., Röttger, U. (2013). Issues Management: Ein Diskurs zwischen Theorie und Praxis. In: O. Hoffjann, S. Huck-Sandhu (eds.). UnVergessene Diskurse. 20 Jahre PR- und Organisationskommunikationsforschung. Wiesbaden: Springer Fachmedien, pp. 465-497.

Jarren, O., Röttger, U. (2009). Steuerung, Reflexierung und Interpenetration: Kernelemente einer strukturationstheoretisch begründeten PR-Theorie. In: U. Röttger (ed.), Theorien der Public Relations. Grundlagen und Perspektiven der PR-Forschung (2nd ed.). Wiesbaden: VS Verlag für Sozialwissenschaften, pp. 29-49.

Kirsch, W. (1992). Kommunikatives Handeln, Autopoiese, Rationalität: Sondierungen zu einer evolutionären Führungslehre. München: Herrsching, Kirsch.

Kühl, S. (2000). Das Regenmacher-Phänomen. Widersprüche und Aberglaube im Konzept der lernenden Organisation. Frankfurt am Main: Campus Verlag.

Long, L.W., Hazleton, V. (1987). Public relations. A theoretical and practical response. Public Relations Review, 13 (2), pp. 3-13.

Luhmann, N. (1996). Social Systems. Stanford, CA: Stanford University Press.

Luhmann, N. (2000). Organisation und Entscheidung. Opladen \& Wiesbaden: VS Verlag für Sozialwissenschaften.

Pawlowsky, P. (1995). Von betrieblicher Weiterbildung zum Wissensmanagement. In: H. Geißler (ed.). Organisationslernen und Weiterbildung. Neuwied, Kriftel, Berlin: Luchterhand, pp. 435-456.

Probst, G.J.B., Büchel, B. (1994). Organisationales Lernen: Wettbewerbsvorteil der Zukunft. Wiesbaden: Gabler.

Senge, P.M. (1990). The Fifth Discipline: The Art and Practice of the Learning Organization. New York: Doubleday.

Weber, M. (2002). Die "Objektivität" sozialwissenschaftlicher und sozialpolitischer Erkenntnis. In: M. Weber, D. Kaesler (eds.), Schriften 1894-1922. Stuttgart: Kröner, pp. 77-149.

Weick, K.E. (1979). Social Psychology of Organizing (2nd ed.). New York: Mc Graw-Hill.

Weick, K.E. (2001). Making Sense of the Organization. Oxford: Blackwell Publishers Ltd.

Weick, K.E., Westley, F. (1996). Organizational learning: affirming an Oxymoron. In: S. Clegg, C. Hardy, W.R. Nord (eds.). Handbook of Organizational Studies. London: Sage, pp. 440-458.

Zerfaß, A., et al. (2014). Corporate communications from the top and center. Comparing experiences and expectations of CEOs and communicators. International Journal of Strategic Communications, 8, pp. 61-78. 